EXTENDED REPORT

\title{
Divergent roles of nitrergic and prostanoid pathways in chronic joint inflammation
}

\author{
S M Day, J C Lockhart, W R Ferrell, J S McLean
}

Ann Rheum Dis 2004;63:1564-1570. doi: 10.1136/ard.2003.017269

See end of article for authors' affiliations

Correspondence to: Correspondence to:
Professor J C Lockhart, Biological Sciences, University of Paisley, Paisley PA1 2BE, Scotland, UK; john.lockhart@ paisley.ac.uk

Accepted 7 February 2004

\begin{abstract}
Background: Nitrergic and prostanoid pathways have both been implicated in inflammatory processes. Objective: To investigate their respective contributions in a rat model of chronic arthritis.

Methods: Male Wistar rats ( $n=4-6 /$ group) received either an intra-articular injection of $2 \%$ carrageenan $/ 4 \%$ kaolin $(\mathrm{C} / \mathrm{K})$ or intra- and periarticular injections of Freund's complete adjuvant (FCA; $10 \mathrm{mg} / \mathrm{ml} M$ tuberculosis). Joint diameter, urinary nitric oxide metabolites $\left(\mathrm{NO}_{\mathrm{x}}\right)$, and prostaglandin $E_{2}\left(P_{G}\right)$ levels were measured as indices of the inflammatory process. A prophylactic and therapeutic (day 5) dose ranging study of an inducible nitric oxide synthase inhibitor, $\mathrm{L}-\mathrm{N}-(1$ iminoethyl)-lysine (L-NIL), and a cyclo-oxygenase-2 (COX-2) inhibitor, SC-236, was performed with the drugs given subcutaneously. Submaximal doses were identified and used for combination studies. Appropriate vehicle controls were included.

Results: L-NIL and SC-236 dose dependently inhibited C/K induced acute joint swelling, the magnitude being greatest when they were given in combination. Both prophylactic and therapeutic administration of SC-236 in the FCA induced model of chronic arthritis produced a dose dependent reduction in all the measures assessed. However, although L-NIL demonstrated similar dose dependent inhibition of urinary $\mathrm{NO}_{x}$ and $P \mathrm{PE}_{2}$ levels, joint swelling was significantly exacerbated in this model. Co-administration of the inhibitors nullified the benefits of SC-236.

Conclusion: Whereas COX-2 derived prostaglandins are proinflammatory in both acute and chronic joint inflammation, NO seems to have divergent roles, being anti-inflammatory in chronic and proinflammatory in acute joint inflammation.
\end{abstract}

nflammation is known to result in increased production of nitric oxide (NO) and prostaglandins. ${ }^{12}$ Interaction between these two mediators may provide an additional point of manipulation of the inflammatory response to prevent debilitating diseases such as rheumatoid arthritis (RA). Our group has previously demonstrated in vitro that inhibiting nitrergic and prostanoid pathways simultaneously in lipopolysaccharide-activated $\mathrm{J} 774$ macrophages provided greater anti-inflammatory benefit than inhibiting either pathway alone, ${ }^{3}$ but this has not yet been studied in vivo.

The nature of the role of NO in inflammation is contentious, with both pro- and anti-inflammatory actions having been reported. The association of NO with inflammation is supported by the increased urinary levels reported in $\mathrm{RA}^{4}$ and adjuvant induced arthritis in rats. ${ }^{5}$ Furthermore, inducible nitric oxide synthase (iNOS), the isoform of NOS induced by inflammatory cytokines, ${ }^{6}$ is expressed in the synovial membrane of patients with $\mathrm{RA}^{78}$ and is up regulated in models of arthritis. ${ }^{90}$ Early work by Stefanovic-Racic et al found that prophylactic, and to a lesser extent therapeutic, administration of the NOS inhibitors, aminoguanidine and $N^{\mathrm{G}}$-monomethyl-L-arginine (L-NMMA), inhibited paw oedema. ${ }^{11}$ Several in vitro and in vivo studies, however, have suggested that NO may have anti-inflammatory actions-for example, exogenous NO donors reduce cytokine induced endothelial cell activation, ${ }^{12}$ inhibit endothelial-leucocyte interactions, ${ }^{13}$ and attenuate vascular inflammation. ${ }^{14}{ }^{15}$ Moreover, Stefanovic-Racic et al found that NO exerts a chondroprotective role in cartilage matrix metabolism. ${ }^{16}{ }^{17}$

Prostaglandins are well known as proinflammatory mediators, and inhibition of cyclo-oxygenase (COX) has long been used in the management of joint inflammation, with more recent strategies selectively targeting the proinflammatory inducible form of the enzyme, COX-2. ${ }^{18}$ Levels of prostaglandin $\mathrm{E}_{2}\left(\mathrm{PGE}_{2}\right)$, the key prostaglandin mediating the cardinal signs of inflammation, are increased in various states of inflammation. ${ }^{19}$ While the constitutive form of COX (COX-1) is expressed in nearly all tissues of the body, COX-2 expression is generally only induced in response to inflammatory stimuli-for example, tumour necrosis factor $\alpha$ $(\mathrm{TNF} \alpha)$, interleukin $1 \beta$, and lipopolysaccharide (LPS). Studies by Sano et $a l^{20}$ and Crofford et $a l^{21}$ show that COX-2 expression in synovial tissue from patients with RA was up regulated by proinflammatory cytokines and down regulated by corticosteroids, strongly supporting an inflammatory role for COX-2 in human joint tissue. Although prostaglandins have a clear role in inflammation, their influence in the development and maintenance of chronic inflammatory arthritis is more complex.

The present study sought to examine in vivo the role of the nitrergic and prostanoid systems in acute and chronic models of arthritis using selective inhibitors for iNOS (L- $N-(1-$ iminoethyl)-lysine (L-NIL)) and COX-2 (SC-236). Given the bank of reports supporting interaction between these pathways, ${ }^{22-28}$ we further investigated the hypothesis that combined inhibition of both nitrergic and prostanoid pathways may offer enhanced anti-inflammatory benefit.

Abbreviations: ANOVA, analysis of variance; $\mathrm{C} / \mathrm{K}, 2 \%$ carrageenan/ $4 \%$ kaolin; COX, cyclo-oxygenase; ELISA, enzyme linked immunosorbent assay; IC $50,50 \%$ inhibitory concentration; iNOS, inducible nitric oxide synthase; L-NIL, (L-N-(1-iminoethyl)-lysine; L-NMMA, $N^{G}$-monomethyl-t-arginine; L-NAME, $N^{\mathrm{w}}$-nitro-l-arginine; LPS, lipopolysaccharide; $\mathrm{NO}_{x}$, nitric oxide metabolites; $\mathrm{PGE}_{2}$, prostaglandin $\mathrm{E}_{2} ; \mathrm{RA}$, rheumatoid arthritis; $\mathrm{TNF} \alpha$, tumour necrosis factor $\alpha$ 


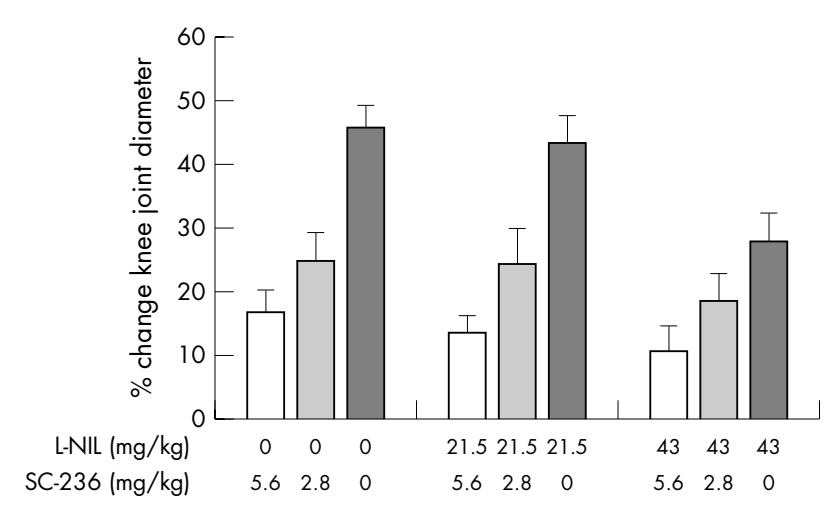

Figure 1 Acute inflammation: knee joint swelling (24 hours) induced by intra-articular injection of carrageenan and kaolin, expressed as a percentage change in knee joint diameter compared with preinjection values. $\mathrm{L}-\mathrm{NIL}$ and SC-236 given in combination resulted in greater inhibition of knee joint swelling than either drug alone $(p<0.01$, two way ANOVA).

\section{MATERIALS AND METHODS \\ Experimental animals}

Experiments were performed in male Wistar rats (300-400 g body weight; Harlan UK Ltd). Animals were housed in standard cages, had food and water available freely, and were maintained in a thermoneutral environment $\left(23 \pm 2^{\circ} \mathrm{C}\right)$. All procedures were performed in accordance with Home Office regulations.

\section{Induction of acute inflammation}

Acute joint inflammation induced by carrageenan is an acute neutrophil driven model of arthritis, which resolves over a period of a week. $\lambda$-Carrageenan $(100 \mu \mathrm{l}$ of $2 \%)$ and $4 \%$ kaolin (wt/vol; Sigma, UK) in saline $(0.9 \%)$ was injected (26$\mathrm{G}$ needle) into one knee joint of animals anaesthetised using a mixture of $2 \%$ halothane, $\mathrm{O}_{2}$, and $\mathrm{N}_{2} \mathrm{O}$. Once recovered from anaesthesia, the animals were returned to their cages. Knee joint swelling was expressed as the percentage change in joint diameter when measured at 24 hours after induction relative to the value before injection.

\section{Induction of chronic inflammation}

The animals were anaesthetised with a $2 \%$ halothane mixture with $\mathrm{O}_{2}$ and $\mathrm{N}_{2} \mathrm{O}$ ( 1 litre/min). The fur surrounding the knee joint of the animal was shaved, and inflammation was induced by intra- and periarticular $(0.5 \mathrm{ml})$ injection of Freund's complete adjuvant (FCA), composed of a $10 \mathrm{mg} / \mathrm{ml}$ solution of $M$ tuberculosis suspended in Freund's incomplete adjuvant (Sigma, UK). Immediately after injection, the knee was flexed and extended repeatedly for about 1 minute. We have successfully demonstrated that this approach in mice gives a robust chronic inflammatory response, which is sustained for many weeks. ${ }^{29}$

\section{Measurement of knee joint swelling}

The joint diameter of the injected knee was measured with modified Vernier callipers (Oditest, Kroeplin, Gmbh, Germany). Measurements were made before and immediately after injection of the joint, and at various times thereafter. There was negligible change in knee joint diameter immediately after injection.

\section{Experimental design}

The inducible isoforms of the key enzymes in the nitrergic and prostanoid pathways, iNOS and COX-2, were selectively inhibited using L-NIL (Alexis Corp, UK) and SC-236 (Pharmacia Corp, USA), respectively.

\section{Acute inflammation}

Animals were randomly assigned to the following groups $(\mathrm{n}=6$ /group): saline vehicle treated; L-NIL treated $(21.5 \mathrm{mg} /$ $\mathrm{kg}$ and $43 \mathrm{mg} / \mathrm{kg})$; SC-236 treated animals $(2.8 \mathrm{mg} / \mathrm{kg}$ and $5.6 \mathrm{mg} / \mathrm{kg}$ ); and all combinations of the above doses for both inhibitors. Drugs or vehicle were given subcutaneously 1 hour before induction of acute inflammation.

\section{Chronic inflammation}

Animals were randomly assigned to the following groups for the dose ranging studies: healthy untreated animals $(\mathrm{n}=4)$; saline vehicle treated FCA animals $(\mathrm{n}=4) ; 0.5 \%$ methylcellulose vehicle treated FCA animals $(n=4)$; L-NIL treated FCA animals (prophylactically and therapeutically; $\mathrm{n}=6$, for both), $21.5 \mathrm{mg} / \mathrm{kg}, 43 \mathrm{mg} / \mathrm{kg}$, and $86 \mathrm{mg} / \mathrm{kg}$; SC-236 treated animals (prophylactically and therapeutically; $\mathrm{n}=6$, for both), $2.8 \mathrm{mg} / \mathrm{kg}, 5.6 \mathrm{mg} / \mathrm{kg}$, and $11.2 \mathrm{mg} / \mathrm{kg}$; submaximal doses were subsequently used to investigate combination therapy: L-NIL (43 mg/kg) and SC-236 (5.6 mg/kg) drug combinations (prophylactically and therapeutically; $\mathrm{n}=6$, for both). Drugs or vehicle were given subcutaneously 1 hour before induction of FCA and daily thereafter for prophylactic treatment, or daily beginning on day 5 for therapeutic treatment.

\section{Drugs}

SC-236 (a gift of Pharmacia Corp, USA) is a COX inhibitor selective for COX-2 with $50 \%$ inhibitory concentration $\left(\mathrm{IC}_{50}\right)$

Table 1 Dose-response data for prophylactic administration of drugs, expressed as a percentage change compared with baseline

\begin{tabular}{|c|c|c|c|c|c|c|c|c|c|}
\hline \multirow[b]{3}{*}{ Day } & \multirow[b]{3}{*}{ NI } & \multicolumn{8}{|l|}{ FCA } \\
\hline & & \multirow[b]{2}{*}{ Vehicle } & \multicolumn{3}{|c|}{ L-NIL (mg/kg) } & \multicolumn{3}{|c|}{$\mathrm{SC}-236(\mathrm{mg} / \mathrm{kg})$} & \multirow{2}{*}{$\begin{array}{l}\text { L-NIL+SC }-236 \\
(\mathrm{mg} / \mathrm{kg}) \\
43+5.6\end{array}$} \\
\hline & & & 21.5 & 43 & 86 & 2.8 & 5.6 & 11.2 & \\
\hline 1 & $6.4(0.2)$ & 80.1 (15.7) & $87.7(1.8)$ & $84.8(11.1)$ & $95.7(1.9)$ & $84.5(1.7)$ & $72.7(6.5)$ & $40.9(1.2)$ & 72.5 (16.3) \\
\hline 10 & $2.1(0.5)$ & $56.4(8.3)$ & $65.6(1.5)$ & 75.7 (8.4) & 78.4 (1.9) & $56.6(1.7)$ & 36.4 (12.3) & $28.0(1.1)$ & 74.2 (1.1) \\
\hline \multicolumn{10}{|c|}{ Urinary $\mathrm{NO}_{x}$} \\
\hline 1 & $-11.5(1.9)$ & $487.6(9.7)$ & 433.6 (1.7) & $125.2(2.5)$ & $96.0(1.3)$ & $434.0(1.6)$ & 422.1 (14.9) & $95.4(1.7)$ & $413.7(2.0)$ \\
\hline 9 & $7.5(0.5)$ & 209.2 (5.2) & $77.8(1.6)$ & $62.9(9.5)$ & 14.8 (1.3) & $194.1(1.1)$ & $200.4(10.3)$ & $116.7(1.6)$ & $68.1(2.8)$ \\
\hline \multicolumn{10}{|c|}{ Urinary $P G E_{2}$} \\
\hline 1 & $3.3(0.2)$ & $144.3(7.6)$ & $142.9(1.9)$ & $121.4(6.6)$ & $101.0(1.4)$ & $141.4(1.0)$ & $113.2(5.5)$ & $104.2(1.3)$ & 115.5 (1.9) \\
\hline 9 & $-2.5(0.5)$ & $45.4(2.4)$ & $43.0(1.1)$ & $34.4(2.4)$ & $31.0(1.2)$ & $41.7(1.1)$ & $25.6(2.7)$ & $13.2(1.1)$ & $26.6(1.3)$ \\
\hline
\end{tabular}



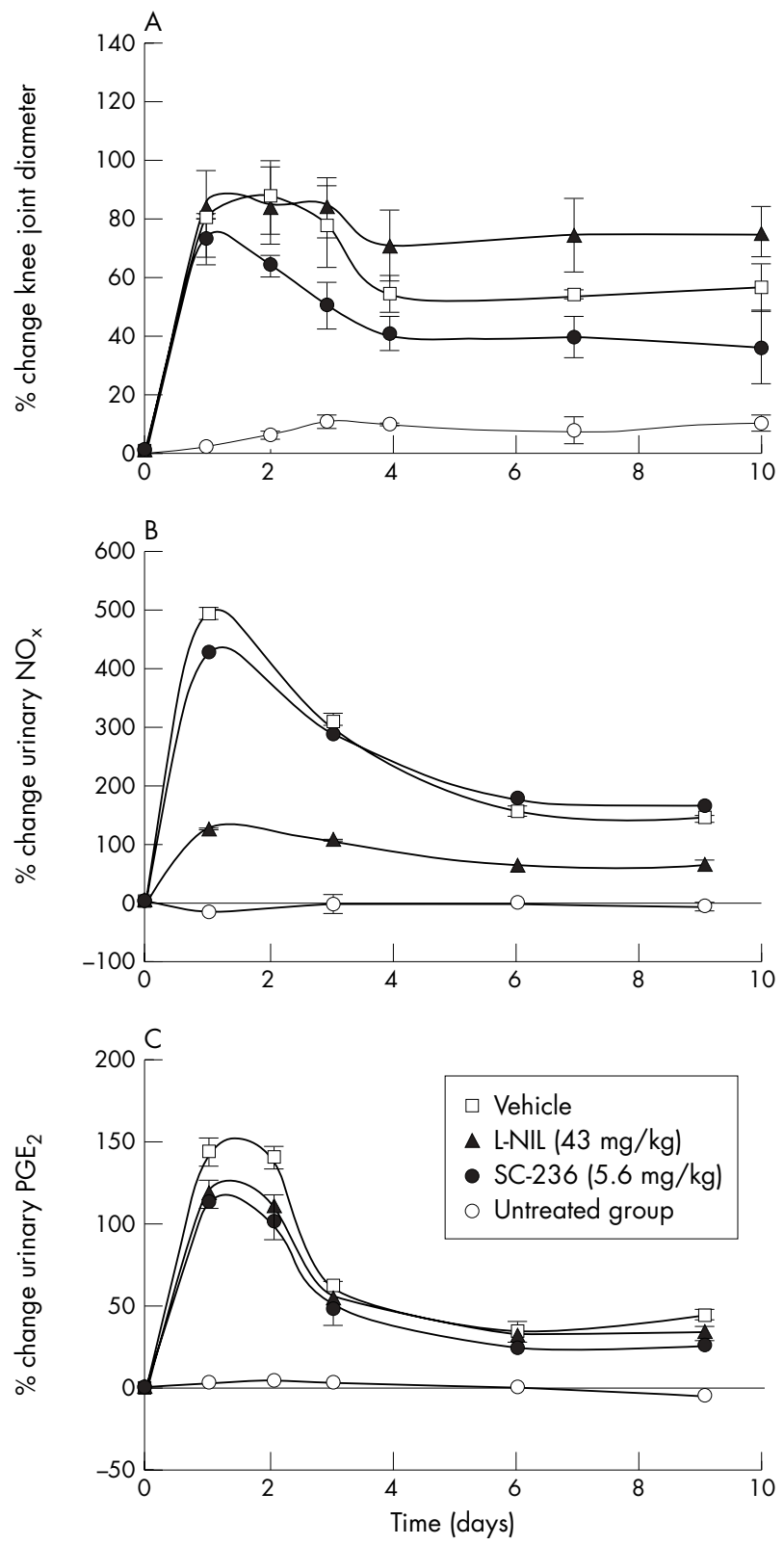

Figure 2 Chronic inflammation-prophylactic administration: $(A)$ knee joint swelling; (B) urinary $\mathrm{NO}_{x}$; and (C) $\mathrm{PGE}_{2}$, expressed as a percentage change compared with preinjection values in response to intra-articular injection of FCA. There was significant joint swelling and increased $\mathrm{NO}_{x}$ and $\mathrm{PGE}_{2}$ production in the vehicle, $\mathrm{L}-\mathrm{NIL}(43 \mathrm{mg} / \mathrm{kg})$, and SC-236 $(5.6 \mathrm{mg} / \mathrm{kg})$ prophylactically treated groups. A noninflamed, untreated group is included for comparison. Values represent means (SEM).

of $0.005 \mu \mathrm{mol} / \mathrm{l}$ compared with $17 \mu \mathrm{mol} / \mathrm{l}$ for COX-1. $.^{30} \mathrm{~L}-\mathrm{NIL}$ (Alexis Corp, Nottingham, UK) is a selective inhibitor of iNOS with IC $_{50}$ of $3.3 \mu \mathrm{mol} / \mathrm{l}$ compared with $92 \mu \mathrm{mol} / \mathrm{l}$ for constitutive NOS. ${ }^{31}$ The vehicle for these drugs was $0.9 \%$ saline for L-NIL and 0.5\% methylcellulose (Sigma, UK) for SC-236. Urethane was obtained from Sigma, UK, and halothane from Concord Pharmaceuticals Ltd, Essex, UK.

\section{Urinary nitrite/nitrate determination}

Urine was collected overnight by placing the animals in metabolic cages at set days before and during the procedure, and later analysed for nitrite/nitrate $\left(\mathrm{NO}_{\mathrm{x}}\right)$ and $\mathrm{PGE}_{2}$ by the
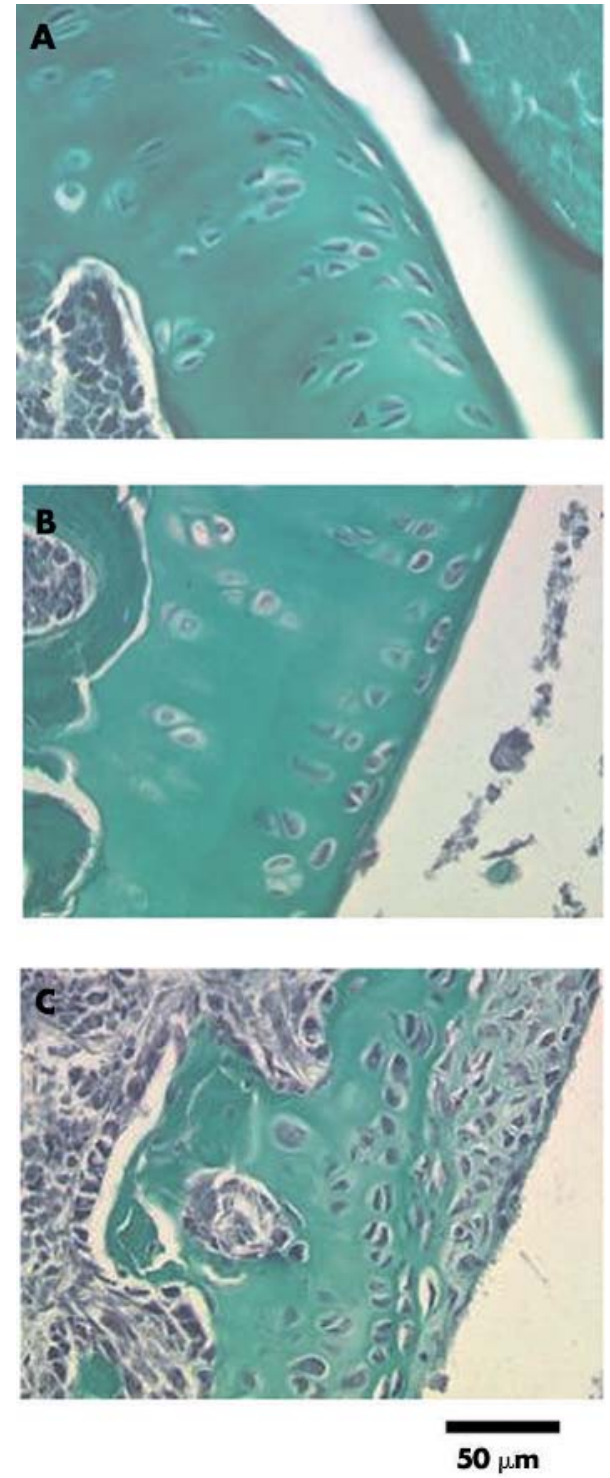

Figure 3 Chronic inflammation-histology: (A) normal (untreated) knee joint; (B) 10 days after induction of FCA in SC-236 treated animals; (C) 10 days after induction of FCA in L-NIL treated animals. Sections stained with haematoxylin, safranin $O$, and fast green.

modified Griess reaction (see below) and enzyme linked immunosorbent assay (ELISA), respectively.

Urinary nitrite/nitrate $\left(\mathrm{NO}_{\mathrm{x}}\right)$ excretion was measured as a marker of NO generation. This was performed using a modified version of the Griess assay. Urine was diluted 10fold with deionised water. Nitrite standards were also prepared to assess the extent of nitrate conversion to nitrite. Samples were pipetted into a 96 well plate, followed by an equivalent volume of freshly prepared vanadium chloride solution (200 mg/25 ml $1 \mathrm{M} \mathrm{HCl}$; Sigma, UK) and immediately followed by Griess reagent. After 30 minutes of colour development at $37^{\circ} \mathrm{C}$, absorbance was measured on a microplate spectrophotometer at $570 \mathrm{~nm}$ with $630 \mathrm{~nm}$ reference filter. Each sample was assayed in triplicate. The detection limit of the assay was $2 \mu \mathrm{mol} / \mathrm{l}$ in deionised water. Nitrite values were corrected for variations in urine concentration by dividing by their corresponding osmolality values, measured using an osmometer (Micro-Osmometer; Camlab, Cambridge, UK). 


\begin{tabular}{|c|c|c|c|c|c|c|c|c|c|}
\hline \multirow[b]{3}{*}{ Day } & \multirow[b]{3}{*}{ NI } & \multicolumn{8}{|l|}{ FCA } \\
\hline & & \multirow[b]{2}{*}{ Vehicle } & \multicolumn{3}{|l|}{ L-NIL (mg/kg) } & \multicolumn{3}{|c|}{$\mathrm{SC}-236(\mathrm{mg} / \mathrm{kg})$} & \multirow{2}{*}{$\begin{array}{l}\text { L-NIL+SC-236 } \\
(\mathrm{mg} / \mathrm{kg})\end{array}$} \\
\hline & & & 21.5 & 43 & 86 & 2.8 & 5.6 & 11.2 & \\
\hline 1 & $2.1(0.7)$ & $95.7(7.8)$ & $101.1(4.5)$ & $92.8(7.8)$ & $96.7(4.8)$ & $108.5(9.7)$ & $93.7(7.9)$ & $102.6(6.7)$ & $98.4(5.8)$ \\
\hline 5 & $2.1(0.4)$ & $73.0(0.9)$ & 77.3 (3.4) & 73.8 (1.8) & 73.6 (1.4) & 74.4 (1.8) & $68.7(4.4)$ & $62.1(2.2)$ & $76.7(2.2)$ \\
\hline 14 & $5.2(0.9)$ & $81.3(2.1)$ & $62.9(1.6)$ & $87.1(7.1)$ & $86.7(1.2)$ & $63.9(2.0)$ & $65.5(3.4)$ & $39.7(1.9)$ & $84.9(2.0)$ \\
\hline \multicolumn{10}{|c|}{ Urinary $N O_{x}$} \\
\hline 1 & $-11.2(0.7)$ & $487.6(14)$ & $480.5(10.0)$ & $492.6(6.8)$ & $481.5(9.4)$ & $477.2(13.0)$ & 490.3 (12) & $486.5(8.4)$ & $491.5(5.2)$ \\
\hline 5 & $7.5(0.5)$ & $209.3(0.5)$ & 227.7 (1.7) & $173.8(0.5)$ & $172.2(2.3)$ & $228.9(1.7)$ & 200.4 (6.3) & $200.3(1.7)$ & $175.7(2.3)$ \\
\hline 14 & $8.1(1.3)$ & $203.6(2.0)$ & $163.3(2.1)$ & $126.9(7.1)$ & $31.5(1.6)$ & 196.0 (3.4) & $195.7(5.7)$ & $141.8(1.8)$ & $134.2(3.3)$ \\
\hline \multicolumn{10}{|c|}{ Urinary $P G E_{2}$} \\
\hline 1 & $3.1(0.7)$ & $144.3(4.5)$ & $140.7(7.1)$ & $145.6(9.4)$ & $148.1(6.8)$ & $149.3(5.2)$ & $141.6(9.5)$ & $139.6(6.2)$ & $142.3(7.1)$ \\
\hline 5 & $-2.5(0.5)$ & $45.4(6.3)$ & 40.8 (1.7) & $53.2(0.5)$ & 40.7 (1.5) & $45.1(2.1)$ & $41.4(6.3)$ & $40.4(1.7)$ & 48.1 (2.7) \\
\hline 14 & $2.2(0.4)$ & $49.3(3.2)$ & $53.3(1.8)$ & $43.7(7.1)$ & $31.5(1.4)$ & $38.8(3.4)$ & $21.4(0.4)$ & $14.5(1.8)$ & $34.2(8.1)$ \\
\hline
\end{tabular}

The dose-response curves were significant $(p<0.001)$ for all measurements (see text).

\section{Urinary $\mathrm{PGE}_{2}$ determination}

Bicyclo-PGE 2 (a stable metabolite of $\mathrm{PGE}_{2}$ ) was quantified by a competitive binding ELISA (Cayman Chemical Company, Ann Arbor, USA). After 100-fold dilution of urine, bicyclo$\mathrm{PGE}_{2}$ was quantified according to the manufacturer's protocol. The 96 well plate was read spectrophotometrically at $410 \mathrm{~nm}$. The sensitivity of the assay was $2 \mathrm{pg} / \mathrm{ml}$. Sample values were corrected for urine concentration.

\section{Histological assessment of arthritis}

Knee joints were decalcified in Kristensen's decalcification fluid (Pioneer Research Chemicals, UK) for 7 days, and $6 \mu \mathrm{m}$ paraffin sections prepared. These were stained with haematoxylin, safranin O-fast green and evaluated by two observers who were unaware of the animal treatment.

\section{Statistical analysis}

Statistical analyses were performed using SigmaStat software (SigmaStat, USA). All data were normally distributed (Kolmogorov-Smirnov test with Lilliefors' correction). Comparison between group values was performed by two way analysis of variance (ANOVA), as indicated in the text. Bonferroni multiple comparison tests were used for post hoc comparisons. All quoted $\mathrm{p}$ values are two tailed; $\mathrm{n}$ values refer to the number of animals examined. Data are presented as mean (SEM).

\section{RESULTS}

\section{Acute inflammation}

Separate and combined administration of L-NIL and SC-236

When given separately, both L-NIL and SC-236 dose dependently ( $\mathrm{p}<0.001$, two way ANOVA) inhibited the acute joint swelling induced by $2 \%$ carrageenan $/ 4 \%$ kaolin $(\mathrm{C} / \mathrm{K})$ (fig 1). Consistent with the in vitro results in J774 macrophages, ${ }^{3}$ the combination of L-NIL $(43 \mathrm{mg} / \mathrm{kg})$ and SC-236 $(5.6 \mathrm{mg} / \mathrm{kg})$ showed greater efficacy than either inhibitor alone $(\mathrm{p}<0.01$, two way ANOVA).

\section{Chronic inflammation}

Separate administration of L-NIL or SC-236 arthritis: prophylactic treatment

Knee joint swelling

Swelling of the rat knee joint was evident within 24 hours of injection of FCA, peaking on day 1 and declining to a plateau thereafter. L-NIL significantly enhanced joint swelling at all three doses, and this was sustained for the duration of the experiment (table $1 ; \mathrm{p}<0.001$, for all times; $\mathrm{n}=6$; two way ANOVA). Post hoc testing showed each drug treatment significantly differed from vehicle treated animals. By contrast, subcutaneous administration of all three doses of SC-236 reduced knee joint swelling (table $1 ; \mathrm{p}<0.001 ; \mathrm{n}=6$; two way ANOVA). Figure $2 \mathrm{~A}$ shows the divergent effects of prophylactic administration of submaximal doses of L-NIL $(43 \mathrm{mg} / \mathrm{kg})$ and SC-236 $(5.6 \mathrm{mg} / \mathrm{kg})$ on knee joint swelling.

Urinary $N O_{x}$ and $P G E_{2}$ levels

Levels of nitrite/nitrate were significantly increased in the urine from vehicle treated animals (table $1 ; \mathrm{p}<0.0001$; one way ANOVA; $n=4$ ) with an initial peak at day 1 which fell to a sustained level from day 6 onwards. As expected, administration of L-NIL significantly reduced the magnitude of $\mathrm{NO}_{\mathrm{x}}$ levels in a dose dependent manner when compared with FCA treated animals at all times observed $(\mathrm{p}<0.0001$; $\mathrm{n}=6$; two way ANOVA). In addition, the COX-2 inhibitor, SC-236, also inhibited the FCA induced increase in $\mathrm{NO}_{\mathrm{x}}$ levels but only significantly at the highest dose (table $\mathrm{l} ; \mathrm{p}<0.0001$; $\mathrm{n}=6$; two way ANOVA). Figure $2 \mathrm{~B}$ shows that L-NIL ( $43 \mathrm{mg}$ / $\mathrm{kg})$, significantly reduced urinary $\mathrm{NO}_{\mathrm{x}}(\mathrm{p}<0.05$ for all times; $\mathrm{n}=6$; Bonferroni post hoc), with SC-236 (5.6 mg/kg) showing no significant difference from vehicle treated animals.

Urinary $\mathrm{PGE}_{2}$ levels were significantly increased in the vehicle treated animals $(\mathrm{p}<0.0001 ; \mathrm{n}=4$; one way ANOVA), peaking at day $\mathrm{l}$ and reaching a plateau by day 6 . Administration of L-NIL gave a dose dependent inhibition of $\mathrm{PGE}_{2}$ levels which was evident from day $\mathrm{l}$ onwards (table $1 ; \mathrm{p}<0.001 ; \mathrm{n}=6$; two way ANOVA). As expected, SC236 dose dependently reduced the magnitude of $\mathrm{PGE}_{2}$ levels when compared with vehicle treated animals (table l; $\mathrm{p}<0.001 ; \mathrm{n}=6$; two way ANOVA). Administration of submaximal doses of L-NIL and SC-236 significantly reduced urinary $\mathrm{PGE}_{2}$ levels when compared with vehicle treated animals $(\mathrm{p}<0.001$ for each compared with FCA treated; $\mathrm{n}=6$; Bonferroni post hoc; fig $2 \mathrm{C}$ ).

\section{Histology}

Examination of the knee joints at conclusion of the experiments showed that the knee joint of control, untreated joints had intact cartilage, with no signs of cellular infiltration (fig 3A). Similarly, examination of knees from the SC-236 treated animals displayed similar histology to the knee joints of the control, untreated animals, although 

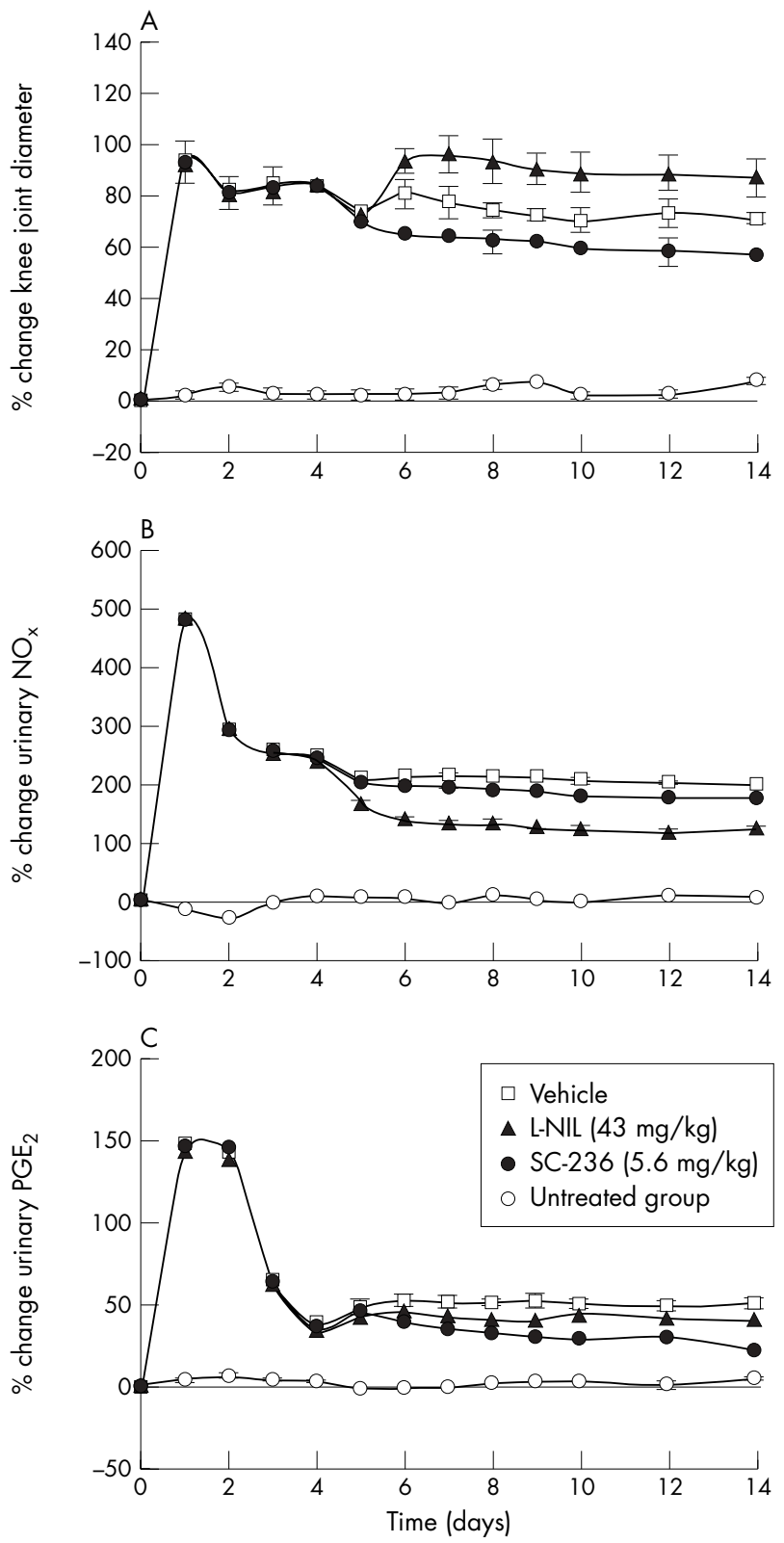

Figure 4 Chronic inflammation-therapeutic administration: (A) knee joint swelling; (B) urinary $\mathrm{NO}_{x}$; and (C) $\mathrm{PGE}_{2}$, expressed as a percentage change compared with pre-injection values in response to intra-articular injection of FCA. There was significant joint swelling and increased $\mathrm{NO}_{x}$ and $\mathrm{PGE}_{2}$ production in vehicle, L-NIL $(43 \mathrm{mg} / \mathrm{kg})$, and SC-236 $(5.6 \mathrm{mg} / \mathrm{kg})$ therapeutically treated groups. A non-inflamed, untreated group is included for comparison. Values represent means (SEM).

cellular exudate was present within the joint space (fig 3B). Interestingly, examination of the joints of L-NIL treated animals disclosed severe arthritic changes, characterised by cellular infiltration and damage to articular cartilage (fig 3C).

Separate administration of L-NIL or SC-236: therapeutic treatment

Knee joint swelling

Therapeutic administration of the NOS and COX inhibitors resulted in divergent effects: L-NIL at the three doses caused a profound exacerbation in knee joint swelling when given at day 5 after FCA induction (table 2; $\mathrm{p}<0.001, \mathrm{n}=6$; two way ANOVA), whereas knee joint swelling was reduced after
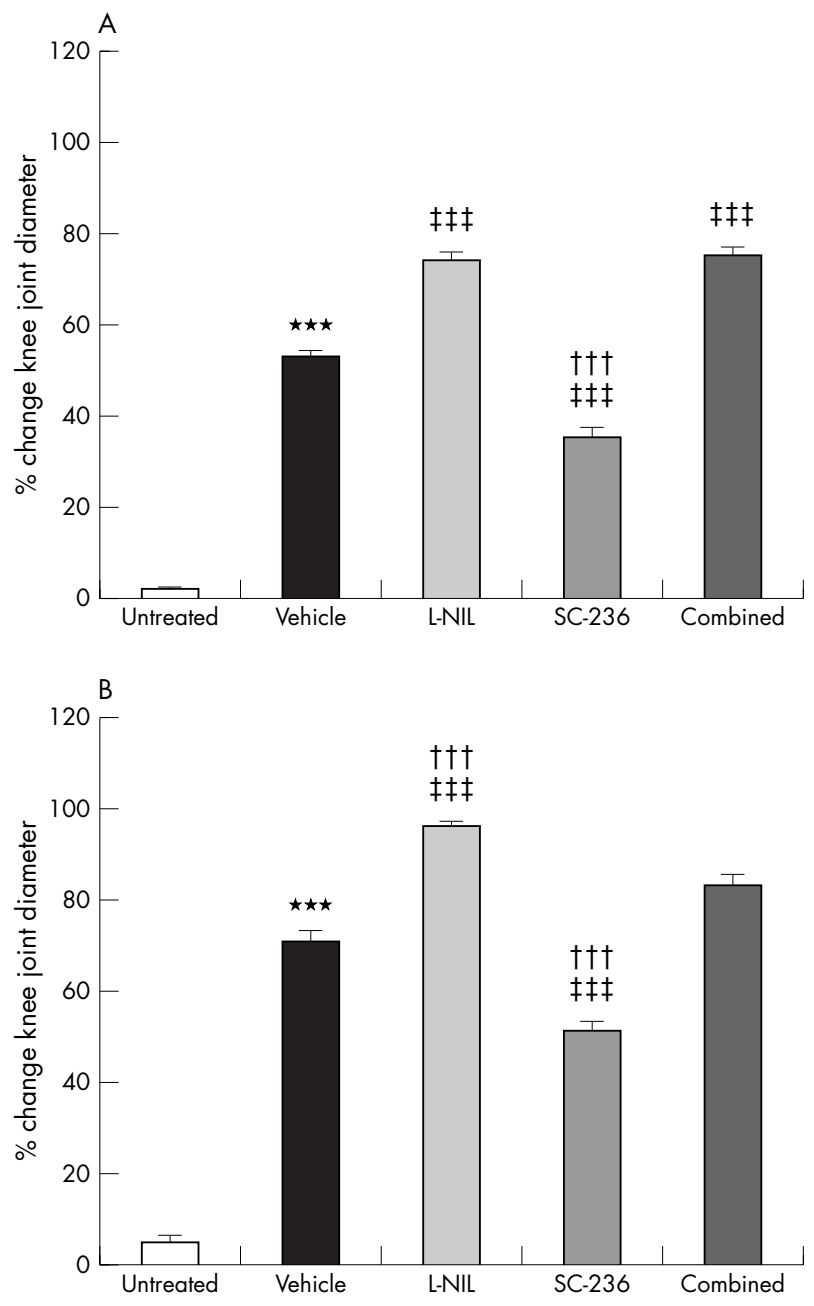

Figure 5 Chronic inflammation-combined administration: Knee joint swelling, expressed as a percentage change compared with preinjection values in response to intra-articular injection of FCA. Combined administration of $\mathrm{L}-\mathrm{NIL}(43 \mathrm{mg} / \mathrm{kg})$ and SC-236 $(5.6 \mathrm{mg} / \mathrm{kg})$,

(A) prophylactically or (B) therapeutically at days 9 and 14, respectively, as compared with untreated and vehicle treated controls. Data for independent administration of each of these drugs (from figs 2 and 3) are also included for comparison. Values represent means (SEM), $n=6$ / group. ${ }^{* * *} \mathrm{p}<0.001$ compared with untreated controls; $¥ \pm \ddagger \mathrm{p}<0.001$ compared with vehicle treated inflamed animals; ††† $p<0.001$ compared with combination treatment inflamed animals (Bonferroni post hoc tests).

administration of SC-236 (table 2; $<<0.0001 ; \mathrm{n}=6$; two way ANOVA). Figure 4A shows the divergent effects when L-NIL $(43 \mathrm{mg} / \mathrm{kg})$ and SC-236 $(5.6 \mathrm{mg} / \mathrm{kg})$ were given separately.

Urinary $N O_{x}$ and $P G E_{2}$ levels

Therapeutic administration of L-NIL resulted in a significant dose dependent reduction in urinary $\mathrm{NO}_{\mathrm{x}}$ levels (table 2; $\mathrm{p}<0.001 ; \mathrm{n}=6$; two way ANOVA). SC-236 also inhibited urinary $\mathrm{NO}_{\mathrm{x}}$ levels in this model, but to a lesser extent than L-NIL (table 2; $\mathrm{p}<0.001 ; \mathrm{n}=6$; two way ANOVA). L-NIL $\left(43 \mathrm{mg} / \mathrm{kg}\right.$ ) significantly reduced urinary $\mathrm{NO}_{\mathrm{x}}$ levels with time when compared with vehicle treated and SC-236 treated animals $(\mathrm{p}<0.05$, from day 5 onwards; $\mathrm{n}=6$; Bonferroni post hoc; fig 4B).

Therapeutic administration of L-NIL reduced the magnitude of urinary $\mathrm{PGE}_{2}$ levels, compared with FCA treated animals, in a dose dependent manner (table 2; $<<0.001$; $\mathrm{n}=6$; two way ANOVA). SC-236 also dose dependently inhibited urinary $\mathrm{PGE}_{2}$ levels (table 2; $\mathrm{p}<0.001 ; \mathrm{n}=6$; two 
way ANOVA). Therapeutic administration of the submaximal doses of L-NIL and SC-236, alone, both significantly reduced urinary $\mathrm{PGE}_{2}$ with time when compared with vehicle treated animals $(\mathrm{p}<0.05 ; \mathrm{n}=6$; Bonferroni post hoc; fig $4 \mathrm{C})$.

\section{Combined administration of L-NIL and SC-236: prophylactic treatment}

Figure 5A shows the combined effect of prophylactic administration of L-NIL ( $43 \mathrm{mg} / \mathrm{kg})$ and SC-236 $(5.6 \mathrm{mg} / \mathrm{kg})$ on knee joint swelling. Combined administration of L-NIL and SC-236 appeared to nullify the anti-inflammatory effect of SC-236, with the magnitude of the joint swelling in the drug combination group differing significantly from SC-236 (table $1 ; \mathrm{p}<0.001 ; \mathrm{n}=6$; Bonferroni post hoc), but not L-NIL treated groups at day 9. Furthermore, combined administration of L-NIL and SC-236 did not significantly reduce urinary $\mathrm{NO}_{\mathrm{x}}$ levels when compared with L-NIL (table 1). Compared with the vehicle treated group, urinary $\mathrm{PGE}_{2}$ levels were significantly reduced by either SC-236 or L-NIL, but were not further reduced by combined administration of these inhibitors (table $1 ; \mathrm{p}<0.001$ for each compared with FCA treated; $\mathrm{n}=6$; Bonferroni post hoc).

\section{Combined administration of L-NIL and SC-236: therapeutic treatment}

As with prophylactic treatment, therapeutic inhibition of the two pathways separately resulted in divergent effects on joint swelling, with L-NIL exacerbating and SC-236 attenuating inflammation. Combined administration of these two agents again negated the anti-inflammatory effect of SC-236 (fig 5B), with the drug combination differing significantly from SC-236 (day 14; $<<0.05$; Bonferroni post hoc; table 2), but not L-NIL alone. The L-NIL and SC-236 combination significantly attenuated urinary $\mathrm{NO}_{\mathrm{x}}$ levels when compared with vehicle treated and SC-236 treated animals $(\mathrm{p}<0.05$ for both comparisons; $\mathrm{n}=6$ /group; Bonferroni post hoc; table 2 ), but not compared with the L-NIL treated group. Combination treatment also reduced urinary $\mathrm{PGE}_{2}$ levels significantly when compared with vehicle treated animals $(\mathrm{p}<0.05 ; \mathrm{n}=6$; Bonferroni post hoc; table 2). No significant difference was seen when the combination group was compared with the L-NIL or SC-236 groups alone.

\section{DISCUSSION}

Using selective inhibitors of iNOS and COX-2, this study sought to examine the role of nitrergic and prostanoid systems in a model of chronic joint inflammation. As far as we know it is the first to investigate parallel inhibition of both pathways, as assessed by changes in urinary $\mathrm{PGE}_{2}$ and NO in Freund's adjuvant model of arthritis, and demonstrates a divergence in the roles of these pathways in chronic inflammatory processes.

The extent of macrophage activity in inflamed RA synovial tissue has been shown to correlate with the severity of the disease. ${ }^{32}$ We have recently reported that combined inhibition of nitrergic and prostanoid systems in primary cultures of LPS activated murine macrophages has greater benefit than separate inhibition of these pathways, ${ }^{3}$ and the present study now extends this to in vivo models of arthritis. The preliminary experiments in the current study were conducted in a $\mathrm{C} / \mathrm{K}$ induced acute model of inflammation, and support the in vitro findings (fig 1). However, these findings could not be extrapolated to chronic joint inflammation. Although prostaglandins are consistently proinflammatory in the in vitro $^{3}$ and in vivo models studied (figs 1, 2A, and 4A), we find evidence in rats for a reversal in the nature of the role played by NO in FCA induced arthritis. Adjuvant induced arthritis is known to be $\mathrm{T}$ cell driven, ${ }^{33}$ whether by systemic or local administration. ${ }^{34}{ }^{35}$ Such models of arthritis are characterised by sustained joint swelling, marked pannus formation, and cartilage erosion. Joint swelling (figs 2A and 4A) and histological assessment (fig 3 ) of joint destruction demonstrated the divergent effect of inhibiting nitrergic and prostanoid pathways on chronic joint inflammation, with SC-236 alleviating and L-NIL exacerbating joint inflammation, suggesting an anti-inflammatory role for iNOS derived nitric oxide.

Clearly the nature of the role of NO, is more complex. In LPS activated J774 macrophages, production of the inflammatory cytokine, TNF $\alpha$, was significantly reduced by combined administration of L-NAME and indometacin, but not by either inhibitor alone. ${ }^{3}$ In the present study, inhibition of iNOS with L-NIL substantially ablated joint swelling in the $\mathrm{C} / \mathrm{K}$ acute model of arthritis. Together these results argue for a proinflammatory role for NO. However, the opposite appears true in the chronic model of arthritis. Here, inhibition of iNOS exacerbates the inflammatory response (figs 2A and 4A), suggesting endogenous NO release has an anti-inflammatory role, opposite to that of prostaglandins and contrary to its role in acute inflammation. The time course of the L-NIL effect was noticeably more rapid when it was given therapeutically (fig 4A) than when given prophylactically (fig 2A). We have previously found that COX-2 induction precedes and is much more rapid in onset than iNOS induction ${ }^{36}$ in the early phase of arthritis. In addition, the exacerbated swelling of the joint was supported by the histological examination of the knees (fig 3C), which showed cartilage damage with cellular infiltration. Although this does not accord with earlier work in the adjuvant model of arthritis, where inhibition of iNOS by L-NIL ${ }^{10}$ or L-NMMA had anti-inflammatory effects, our findings are supported by more recent studies in other chronic models. Septic arthritis ${ }^{37}$ and antigen induced arthritis ${ }^{38}$ have both been reported to be exacerbated in iNOS knockout mice, suggesting a role for NO in synovial defence, consistent with the profound increase in joint destruction seen in L-NIL treated rats with streptococcal cell wall induced arthritis. ${ }^{39}$ Veihelmann et al reported similar findings in mice, with L-NIL producing an increased joint swelling in antigen induced arthritis at day $7 .^{40}$

Clearly then, inhibition of $\mathrm{NO}$ is not an appropriate therapeutic strategy in this chronic model of arthritis. Prophylactic and therapeutic L-NIL administration not only exacerbated the extent of chronic inflammation but also nullified the anti-inflammatory benefit of SC-236 when given in combination. Moreover, our study reports the new finding in the adjuvant model that administration of a selective COX-2 inhibitor reduces not only prostaglandins but also NO production. Because the latter appears to have antiinflammatory actions in chronic inflammation, this indirect effect may limit the therapeutic efficacy of COX-2 inhibitors, supporting the move towards a new class of antiinflammatory drugs based on the coupling of NO donors with non-steroidal anti-inflammatory drugs or COX-2 inhibitors. While recent studies using nitroaspirin or paracetamol demonstrated anti-inflammatory activity with reduced gastrotoxicity, ${ }^{41-43}$ our work further suggests that coupling selective COX-2 inhibitors with NO releasing agents may improve therapeutic efficacy of this class of COX inhibitors.

The study design used L-NIL and SC-236 to inhibit the increase in $\mathrm{NO}$ and prostaglandin production, respectively, and this was clearly achieved. Consistent with published reports, we also found evidence for cross talk between these pathways, with L-NIL and SC-236 reducing urinary PGE $_{2}$ and NO levels, respectively. It has been shown that NO activates COX, an important transduction mechanism for NO actions in many tissues and organs..$^{23} 38$ In addition, endogenous NO has been shown to have a critical role in the stimulation of COX-2 in the mouse macrophage cell line RAW 264.7, ${ }^{24}$ 
probably interacting with the iron-haem centre at the active site of COX-2, leading to the activation of COX enzymes through soluble guanylase cyclase. On the other hand, NO has been observed to inhibit the synthesis of COX in rat Kupffer cells. ${ }^{26}$ The inhibiting effect of NO on COX seems to derive from the scavenger ability of the NO radical and from the ability of $\mathrm{NO}$ to reduce the ferric active enzyme to the ferrous inactive form. ${ }^{26} \mathrm{PGE}_{2}$ and $\mathrm{NO}$ increase the levels of cGMP or cAMP in various effector cells (macrophages, platelets, etc), ${ }^{24}$ thereby confirming the synergistic effect on the regulation of the immune response.

In conclusion, the prostanoid system is consistently proinflammatory both in vitro and in all in vivo models of inflammation studied. The role of the nitrergic system is more complex. Whereas it appears to be proinflammatory both in vitro and in our carrageenan model of acute inflammation, it has an anti-inflammatory role in chronic inflammation. The divergence in the roles of nitrergic and prostanoid systems, and the finding that COX-2 inhibition reduces $\mathrm{NO}$ as well as prostaglandin production, identifies NO releasing COX-2 inhibitors as worthy of further investigation in the management of arthritis.

\section{ACKNOWLEDGEMENTS}

This work was supported by University of Paisley research funds and Pharmacia Corporation.

We gratefully acknowledge the assistance of Marion Drew and Lynette Dunning.

\section{Authors' affiliations}

S M Day, J C Lockhart, J S McLean, Biological Sciences, University of Paisley, Paisley PA1 2BE, Scotland, UK

W R Ferrell, Centre for Rheumatic Diseases, Royal Infirmary, Glasgow G31 2ER, Scotland, UK

\section{REFERENCES}

1 Coleman JW. Review: Nitric oxide in immunity and inflammation. Int Immunopharmacol 2001;1:1397-406.

2 Prete PE, Gurakar-Osborne A. The contribution of synovial fluid lipoproteins in the chronic synovitis of rheumatoid arthritis. Prostaglandins 1997; 54:689-98.

3 Day SM, McLean JS, Lockhart JC, Ferrell WR. Combined inhibition of nitrergic and prostanoid pathways in $\mathrm{J774}$ macrophages. Clin Exp Rheumatol 2003;21:625-31

4 Ueki Y, Miyake S, Tominaga Y, Eguchi K. Increased nitric oxide levels in patients with rheumatoid arthritis. J Rheumatol 1996;23:230-6.

5 Stefanovic-Racic M, Meyers K, Meschter C, Coffey JW, Hoffman RA, Evans $\mathrm{CH}$. N-monomethyl arginine, an inhibitor of nitric oxide synthase, suppresses the development of adjuvant arthritis in rats. Arthritis Rheum 1994;37:1062-9

6 Bingham $\mathrm{CO} 3 \mathrm{rd}$. he pathogenesis of rheumatoid arthritis: pivotal cytokines involved in bone degradation and inflammation. J Rheumatol Suppl 2002:65:3-9.

7 Mclnnes IB, Leung B, Field M, Wei X-Q, Huang F-P, Sturrock RD, et al. Production of nitric oxide in the synovial membrane of rheumatoid and osteroarthritis patients. J Exp Med 1996;184:1519-24.

8 Sakurai H, Kohsaka H, Liu M-F, Higashiyama H, Hirata Y, Kanno K, et al. Nitric oxide production and inducible nitric oxide synthase expression in inflammatory arthritides. J Clin Invest 1995;96:2357-63.

9 McCartney-Francis NL, Allen JB, Mizel DE, Albina JE, Xie Q-W, Nathan CF, et al. Suppression of arthritis by an inhibitor of nitric oxide synthase. J Exp Med 1993; 178:749-54.

10 Connor JR, Manning PT, Settle SL, Moore WM, Jerome GM, Webber RK, et al. Suppression of adjuvant-induced arthritis by selective inhibition of inducible nitric oxide synthase. Eur J Pharmacol 1995;273:15-24

11 Stefanovic-Racic M, Meyers K, Meschter C, Coffey JW, Hoffman RA, Evans $\mathrm{CH}$. Comparison of the nitric oxide synthase inhibitors, methylarginine and aminoguanidine as prophylactic and therapeutic agents in rat adjuvant arthritis. J Rheumatol 1995;22:1922-8

12 De Caterina R, Libby P, Peng HB, Thannickal VJ, Rajavashisth MA, Gimbrone MA, et al. Nitric oxide decreases cytokine-induced endothelial activation: nitric oxide selectively reduces endothelial expression of adhesion molecules and proinflammatory cytokines. J Clin Invest 1995;96:60-8.

13 Cepinskas G, Lush CW, Kvietys PR. Anoxia/reoxygenation-induced tolerance with respect to polymorphonuclear leukocyte adhesion to cultured endothelia cells. A nuclear factor-kappa B-mediated phenomenon. Circ Res 1999;84:103-12.

14 Khan BV, Harrison DT, Olbrych MT, Alexander RW, Medford RM. Nitric oxide regulates vascular cell wall adhesion molecule 1 gene expression and redox-sensitive transcriptional events in human vascular endothelial cells. Proc Natl Acad Sci USA 1996;93:9114-19.

15 Stoclet JC, Muller B, Andriantsitohaina R, Kleschyov A. Overexpression of nitric oxide in pathophysiology of blood vessels. Biochemistry (Mosc) 1998;63:826-32

16 Stefanovic-Racic M, Morales TI, Taskiran D, Mclntyre LA, Evans CH. The role of nitric oxide in proteoglycan turnover by bovine articular cartilage organ cultures. J Immunol 1996;156:1213-20.

17 Stefanovic-Racic M, Mollers MO, Miller LA, Evans CH. Nitric oxide and proteoglycan turnover in rabbit articular cartilage. J Orthop Res 1997; 15:442-9.

18 Emery P. Review: Clinical implications of selective cyclooxygenase-2 inhibition. Scand J Rheumatol Suppl 1996;102:23-8.

19 Davies P, Maclntyre DE. Prostaglandins and inflammation. In: Gallin Jנر Goldstein IM, Snyderman R, eds. Inflammation: basic principles and clinical correlates. New York: Raven Press, 1992:123-37.

20 Sano H, Hla T, Maier JAM, Crofford U, Case JP, Maciag T, et al. In vivo cyclooxygenase expression in synovial tissues of patients with rheumatoid arthritis and osteoarthritis and rats with adjuvant and streptococcal cell wall arthritis. J Clin Invest 1992;89:97-108.

21 Crofford U, Wilder RL, Ristimaki AP, Sano H, Remmers EF, Epps HR, et al. Cyclooxygenase- 1 and -2 expression in rheumatoid synovial tissues: effects of interleukin-1 $\beta$, phorbol ester and corticosteroids. J Clin Invest 1994:93:1095-101

22 Corbett JA, Kwon G, Turk J, McDaniel ML. IL-1 beta induces the coexpression of both nitric oxide synthase and cyclooxygenase by islets of Langerhans: activation of cyclooxygenase by nitric oxide. Biochemistry 1993:32:13767-70.

23 Novaro V, Rettori V, Gonzalez E, Jawerbaum A, Faletti A, Canteros G, et al. Interaction between uterine PGE and $P G E_{2}$ alpha production and the nitridergic system during embryonic implantation in the rat. Prostaglandins 1996:51:363-76.

24 Salvemini D, Misko TP, Masferrer JL, Seibert K, Currie MG, Needleman P. Nitric oxide activates cyclooxygenase enzymes. Proc Natl Acad Sci USA 1993;90:7240-4

25 Salvemini D, Settle SL, Masferrer JL, Seibert K, Currie MG, Needleman P. Regulation of prostaglandin production by nitric oxide; an in vivo analysis. Br J Pharmacol 1995;114:1171-8.

26 Stadler J, Harbrecht BG, Di Silvio M, Curran RD, Jordan ML, Simmons RL, et al. Endogenous nitric oxide inhibits the synthesis of cyclooxygenase products and interleukin- 6 by rat Kupffer cells. J Leukocyte Biol 1993;53:165-72.

27 Swierkosz TA, Mitchell JA, Warner TD, Botting RM, Vane JR. Co-induction of nitric oxide synthase and cyclo-oxygenase: interactions between nitric oxide and prostanoids. Br J Pharmacol 1995; 114:1335-42.

28 Tetsuka T, Daphna-lken D, Srivastava SK, Baier LD, DuMaine J, Morrison AR. Cross-talk between cyclooxygenase and nitric oxide pathways: prostaglandin $\mathrm{E}_{2}$ negatively modulates induction of nitric oxide synthase by interleukin 1 . Proc Natl Acad Sci USA 1996;91:12168-72.

29 Ferrell WR, Lockhart JC, Kelso EB, Dunning L, Plevin R, Meek SE, et al. Essential role for proteinase-2 activated receptor- 2 in arthritis. $J$ Clin Invest 2003;111:35-41.

30 Gierse JK, McDonald JJ, Hauser SD, Rangwala SH, Koboldt CM, Seibert K. A single amino acid difference between cyclooxygenase -1 (COX-1) and -2 (COX-2) reverses the selectivity of COX-2 specific inhibitors. J Biol Chem 1996;271:15810-14

31 Alderton WK, Cooper CE, Knowles RG. Nitric oxide synthases: structure, function and inhibition. Biochem J 2001;357:593-615.

32 Kinne RW, Brauer R, Stuhlmuller B, Palombo-Kinne E, Burmester GR. Review: Macrophages in rheumatoid arthritis. Arthritis Res 2000;2:189-202.

33 van Eden W, Waksman $\mathrm{BH}$. Immune regulation in adjuvant-induced arthritis. Arthritis Rheum 2003;48:1788-96.

34 Cicala C, lanaro A, Fiorucci S, Calignano A, Bucci M, Gerli R, et al. NO naproxen modulates inflammation, nociception and downregulates $\mathrm{T}$ cell response in rat Freund's adjuvant arthritis. Br J Pharmacol 2000;130:1399-405.

35 Hood VC, Cruwys SC, Urban L, Kidd BL. The neurogenic contribution to synovial leucocyte infiltration and outer outcome measures in a guinea pig model of arthritis. Neurosci Lett 2001;299:201-4.

36 Egan CG, Lockhart JC, Ferrell WR, Day SM, McLean JS. Pathophysiological basis of acute inflammatory hyperaemia in the rat knee: roles of cyclooxygenase-1 and -2. J Physiol 2002;539:579-89.

37 Mclnnes IB, Leung B, Wei XQ, Gemmell CC, Liew FY. Septic arthritis following Staphylococcus aureus infection in mice lacking inducible nitric oxide synthase. J Immunol 1998;160:308-15.

38 Veihelmann A, Landes J, Hofbauer A, Dorger M, Refior HJ, Messmer K, et al. Exacerbation of antigen-induced arthritis in inducible nitric oxide synthasedeficient mice. Arthritis Rheum 2001;44:1420-7

39 McCartney-Francis NL, Song XY, Mizel DE, Wahl SM. Selective inhibition of inducible nitric oxide synthase exacerbates erosive joint disease. J Immunol $2001 ; 166: 2734-40$.

40 Veihelmann A, Hofbauer A, Krombach F, Dorger M, Maier M, Refior HJ, et al. Differential function of nitric oxide in murine antigen-induced arthritis. Rheumatology (Oxford) 2002;41:509-17.

41 Al-Swayeh OA, Clifford RH, del Soldato P, Moore PK. A comparison of the anti-inflammatory and anti-nociceptive activity of nitroaspirin and aspirin Br J Pharmacol 2000;129:343-50

42 Paul-Clark M, Del Soldato P, Fiorucci S, Flower RJ, Perretti M. 21-NO prednisolone is a novel nitric oxide-releasing derivative of prednisolone with enhanced anti-inflammatory properties. Br J Pharmacol 2000;131:1345-54.

43 Colville-Nash PR, Willoughby DA. COX-1, COX-2 and articular joint disease: a role for chondroprotective agents. Biorheology 2002;39:171-9. 